Research Article

\title{
Innovative Process to Enrich Carbon Content of EFB-Derived Biochar as an Alternative Energy Source in Ironmaking
}

\author{
Hadi Purwanto, Alya Naili Rozhan (D), and Hamzah Mohd Salleh \\ Faculty of Engineering, IIUM, P.O. Box 10, 50728 Kuala Lumpur, Malaysia \\ Correspondence should be addressed to Alya Naili Rozhan; alyanaili@iium.edu.my \\ Received 26 May 2017; Revised 15 September 2017; Accepted 8 January 2018; Published 14 March 2018 \\ Academic Editor: Zhiqiang Zhang \\ Copyright ( $) 2018$ Hadi Purwanto et al. This is an open access article distributed under the Creative Commons Attribution License, \\ which permits unrestricted use, distribution, and reproduction in any medium, provided the original work is properly cited.
}

This paper describes the mechanism of a developed process-an integrated pyrolysis-tar decomposition process-to produce oil palm empty fruit bunch- (EFB-) derived biochar with additional solid carbon within the biochar bodies, produced by decomposition of tar vapor on its pore surface, using the chemical vapor infiltration (CVI) method. The product, carbon-infiltrated biochar, was characterized to investigate the possibility to be used as partial coke breeze replacement in ironmaking. Carboninfiltrated biochar is proposed to be utilized for a sintering process that could reduce the consumption of coke and $\mathrm{CO}_{2}$ emission in iron-steel industry.

\section{Introduction}

Being one of the largest palm oil producers, Malaysia has abundance of oil palm residues generated throughout the year. The high volume of oil palm biomass residues incurs high management and disposal costs. The inefficiency of waste management also causes environmental deterioration because of the natural methanation process from biomass dumping [1].

We are interested in the utilization of oil palm empty fruit bunch (EFB), biomass that is abundantly available but marginally utilized in Malaysia. One of the thermochemical methods to harness biomass energy is pyrolysis-a process that produces biochar, biotar, and gases [2]. Gases produced can be directly used as a renewable fuel source, mainly in electric power generation in Malaysia. Biochar (the main product of slow pyrolysis) and biotar (the main product of fast pyrolysis) contain carbon that can be collected and used as a fuel source as well. Different pyrolysis conditions resulted in different products, and each pyrolysis process has to be well executed by following the objectives of the biomass treatment. Several techniques have been carried out by researchers to obtain the desired products, and they are mostly achieved by controlling the important processing parameters such as temperature and heating rates.
This paper discusses the mechanism of carbon-infiltrated biochar production by the integrated pyrolysis-tar decomposition process. The experimental part of the production was already presented [3], which was a combination of slow and fast pyrolysis processes of coarse and fine EFB particles, respectively. Slow pyrolysis of coarse EFB produces biochar that is highly porous and is able to be utilized as a substrate for the biotar decomposition process to take place. Chemical vapor infiltration (CVI) technology was employed to implement integrated fast pyrolysis-tar decomposition over porous EFB biochar-to produce a value-added EFB biochar.

An important product of using the technology is carboninfiltrated biochar containing increased carbon content and calorific value, which is able to partially substitute coke breeze. Coke breeze is generally a by-product of metallurgical coke production for blast furnace, and it is in the form of fine particles. Coke breeze has been used in a sintering machine as a heat source. Carbon-infiltrated biochar, with increased carbon but decreased volatile matters content, can be considered as a supplementary fuel in a sintering plant to reduce the usage of coke breeze. Utilization of an EFB-derived product to partially substitute this fossil fuel is expected to reduce $\mathrm{CO}_{2}$ emission into the environment. 


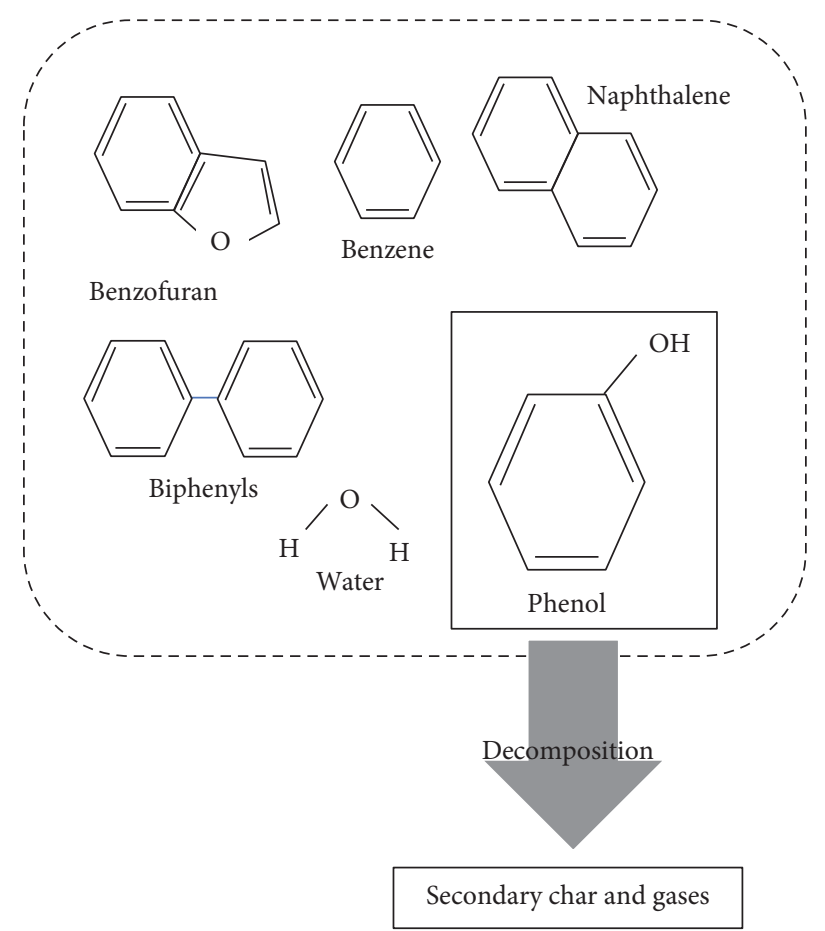

(a)

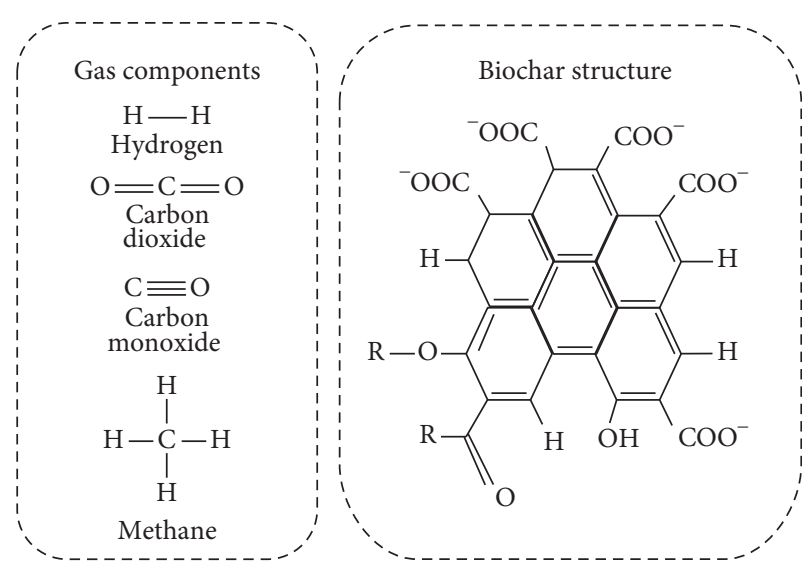

(b)

Figure 1: (a) Chemical structure of biotar components produced by the fast pyrolysis process at $500-600^{\circ} \mathrm{C}$. (b) Chemical structures of gas components and biochar produced by the pyrolysis process.

\section{Characterization Method}

Carbon-infiltrated biochar produced using the integrated pyrolysis-tar decomposition process was characterized for its carbon type and microstructure, as well as to understand the mechanism of the developed process. This carbon deposition process came from decomposition of EFB-derived biotar that took place within the pores of EFB-derived biochar. The conversion of EFB into porous biochar involved decomposition of its components, hemicellulose, cellulose, and lignin. The chemical and physical properties of deposited carbon within the porous biochar were investigated. The chemical structures for components of tar produced by fast pyrolysis, components of gases, and structure of biochar are presented.

In order to study the physical properties of the carboninfiltrated biochar, FE-SEM observation was performed. In relation to the morphologies, pore size distribution of biochar samples before and after tar carbonization was investigated by adsorption isotherms of nitrogen gas on meso- and micropores and the data were collected by employing the DubininAstakhov (DA) method. This method was chosen because it is the most suitable method for biochar, a heterogenous carbonaceous material.

The deposited carbon within the porous biochar was analyzed using the Renishaw inVia micro-Raman spectrometer, equipped with a CCD detector to investigate its $\mathrm{sp}^{3}$ content. The spectra for measurement were selected to be in the range of $900-2000 \mathrm{~cm}^{-1}$, and the measurement was done at least three times to confirm reproducibility.
The properties of carbon-infiltrated biochar were then compared to those of the commercial coke breeze. This material is proposed to be an alternative or a partial substitute to coke breeze in a sintering machine for ironmaking.

\section{Results and Discussion}

Generally, for a lignocellulosic biomass such as EFB, cellulose and hemicellulose decompose into volatiles, whereas lignin normally decomposes into residual ash or biochar depending on the process parameters [4]. Figure 1 (a) presents the structure of tar components produced from the fast pyrolysis process at $500-600^{\circ} \mathrm{C}$ adapted from a review done by Li and Suzuki [5]. The main component in tar produced at these temperatures is phenol, and phenol is a product based from lignin. Therefore, this tar was anticipated to be able to decompose into a large amount of pyrolytic carbon or secondary char, as compared to tar produced at other temperatures. Figure 1(b) depicts the structure of gases and biochar produced in this process.

Figure 2 shows the FE-SEM photos of biochar materials at $100,000 \mathrm{x}$ magnification. This result revealed the shape of biochar pores that appeared to be similar to nano-sized cracks. This clearly supports the notion that the EFB biochar was a heterogeneous material consisting of micropores, mesopores, and macropores. It could be seen that the pores narrowed after the tar carbonization process within the pores. Figure 3 shows the pore size distributions of biochar 


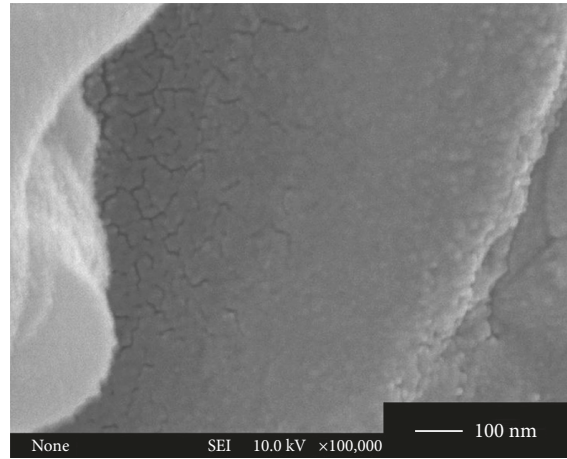

(a)

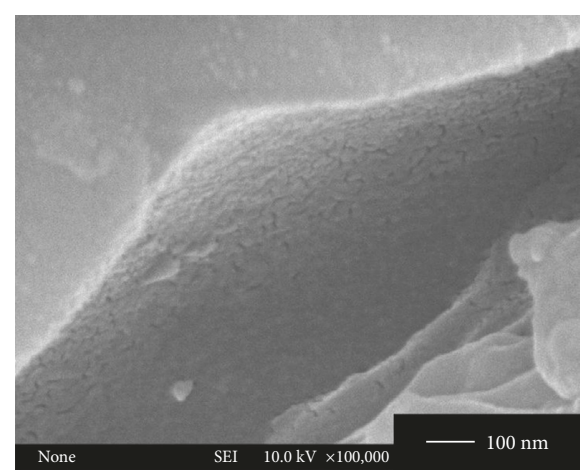

(b)

Figure 2: Morphology of biochar particles showing the shape of the pores (magnification 100,000x). (a) Biochar produced at $400^{\circ} \mathrm{C}$; (b) biochar after carbon deposition within the pores.

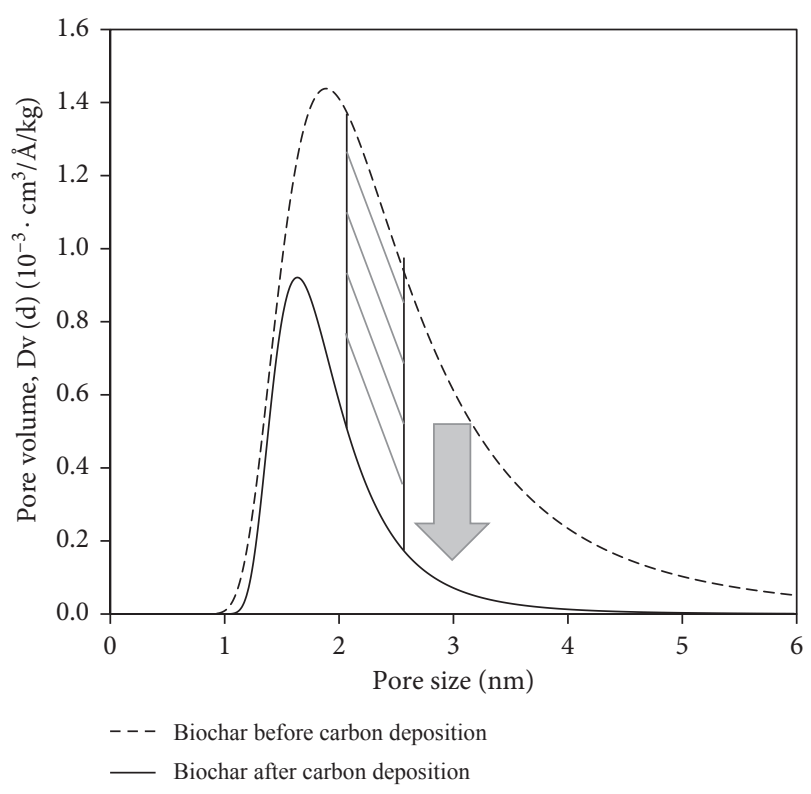

FIGURE 3: Changes in pore size distribution of biochar particles before and after carbon deposition using the Dubinin-Astakhov (DA) method.

before and after tar carbonization analyzed using the nitrogen adsorption method. The Dubinin-Astakhov equation was employed for this type of material and presented by a nonlinear curve fitting to the adsorption isotherm. From this figure, it can be clearly seen that the pores were "consumed" after the tar carbonization process, and pores with $2.0-2.5 \mathrm{~nm}$ size range were found to have the most "pore consumption." This phenomenon was attributed to the carbon deposition within the pores. It can be deduced that, for biochar, $2-2.5 \mathrm{~nm}$ is the range of pore size suitable for the carbon deposition process. In addition, the process to produce more pores of the mentioned size range in a biochar must be controlled by using slow heating rate and low processing temperature.

Figure 4 presents the types of diffusion in porous materials, and these include molecular diffusion, Knudsen diffusion, and a mixture of both diffusion types [6]. In relation to the study of the CVI process within biochar,
Knudsen diffusion was the most favorable diffusion type to ensure that the maximum amount of carbon could be deposited within the pore network in the biochar particles. The vapor diffused through the macropores to reach the mesopores where the decomposition took place, to finally fill up the pores with carbon deposit. Figure 5 presents the mechanism of Knudsen diffusion in relation with this tar carbonization process by the CVI method.

The chemical reaction of tar decomposition to produce carbon deposit is as described below:

$$
\begin{aligned}
\operatorname{Tar}\left(\mathrm{C}_{n} \mathrm{H}_{m}\right)+\mathrm{CO}_{2}+\mathrm{H}_{2} \mathrm{O} \rightarrow & \mathrm{C}_{n-1} \mathrm{H}_{m}+\mathrm{C}+\mathrm{H}_{2}+\mathrm{CO} \\
& +\mathrm{CH}_{4}+\mathrm{C}_{2} \mathrm{H}_{x} \\
& + \text { other hydrocarbons }
\end{aligned}
$$

Smaller pore sizes and low reaction temperatures were particularly important to ensure that a pure Knudsen diffusion occurred so that the pores were not clogged, as they would be if molecular diffusion also came into effect. Small pore size would enhance the colliding of the molecules with the walls which were the pore surface. In addition, lowtemperature reaction is necessary so that the molecules move slowly, suppressing the possibility for them to collide with each other. In this study, tar vapor decomposed into solid carbon and gases when the molecules collided with the pore surface, leaving the solid carbon deposited properly on the pore surface, which consequently could result in the pores to be filled up with this additional carbon to the maximum amount possible. For larger pore sizes, molecular diffusion will take place where the tar will mostly be decomposed into gases instead of solid carbon. This type of diffusion might also cause clogging, which leads to very little or no proper deposition of solid carbon.

On the other hand, low reaction temperature for tar carbonization was also important to avoid unwanted reactions from taking place during the process that could lead to decrease of carbon content of the final product. Reactions that may take place during the tar carbonization process are methanation and Boudouard reactions. The reactions are as described below: 


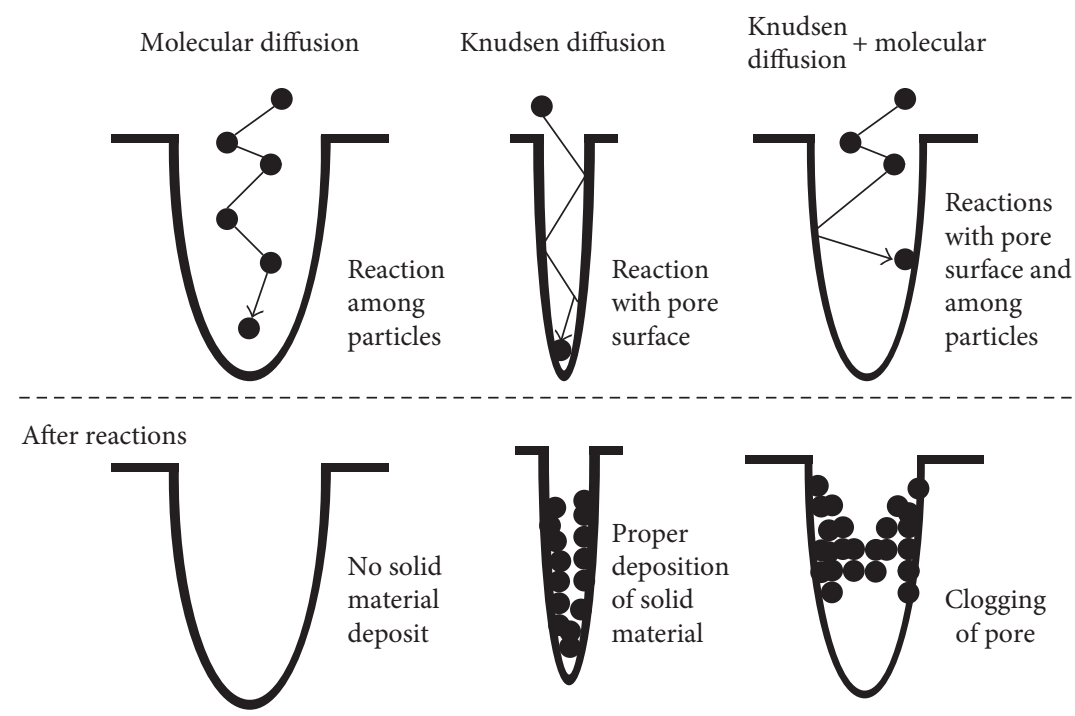

Figure 4: Types of diffusion in porous materials.

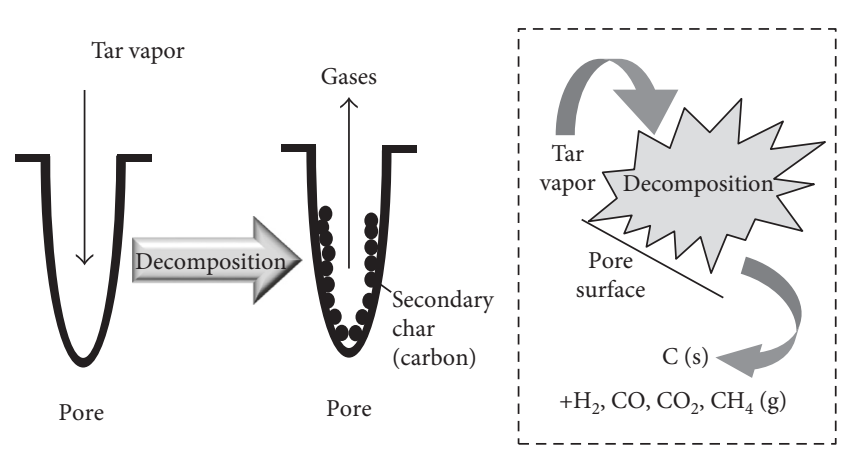

Figure 5: Mechanism of Knudsen diffusion to decompose tar vapor into carbon and gases by the CVI method.

$$
\text { methanation : } \begin{aligned}
\mathrm{CH}_{4}+\mathrm{H}_{2} \mathrm{O} & \leftrightarrow \mathrm{CO}+3 \mathrm{H}_{2} \\
\mathrm{CO}_{2}+4 \mathrm{H}_{2} & \leftrightarrow \mathrm{CH}_{4}+2 \mathrm{H}_{2} \mathrm{O} \\
\mathrm{C}+2 \mathrm{H}_{2} & \leftrightarrow \mathrm{CH}_{4}
\end{aligned}
$$$$
\text { Boudouard : } \mathrm{C}+\mathrm{CO}_{2} \leftrightarrow 2 \mathrm{CO}
$$

Standard methanation and Boudouard reactions occurred at around $700^{\circ} \mathrm{C}$ and $680^{\circ} \mathrm{C}$, respectively. However, if the carbon is of amorphous type with high porosity, the temperatures required for these reactions to take place might be lower than those reported. In addition, for the Boudouard reaction, as the temperature increased further, production of $\mathrm{CO}$ would be more likely to occur which in turn could cause the carbon content of biochar to be consumed, reducing the total amount of solid carbon.

Figure 6 shows the Raman spectra of deposited carbon from the tar carbonization process by utilization of EFB and those of metallurgical coke breeze for comparison. The Raman spectra were characterized by two strong main peaks: D (Defect of Disorder) peak and G (Graphitic) peak. In relation to ideal graphitic lattice, $D$ peak and $G$ peak appeared at around $1350 \mathrm{~cm}^{-1}$ and $1580 \mathrm{~cm}^{-1}$, respectively [7].
There are few methods to evaluate the disordered structure of a material based on Raman spectra, and these include peak intensity ratio, $G$ peak position, and peak area ratio $[8,9]$. Using the $\mathrm{D}$ and $\mathrm{G}$ peak intensities, $I_{\mathrm{D}}$ and $I_{\mathrm{G}}$, respectively, cluster diameter of the structure can be estimated using the ratio of $I_{\mathrm{D}}$ to $I_{\mathrm{G}}\left(I_{\mathrm{D}} / I_{\mathrm{G}}\right)$. In addition, the $\mathrm{sp}^{3}$ fraction of an amorphous carbon can be calculated by using the $\mathrm{G}$ peak position, $\omega_{\mathrm{G}}[10]$.

Figure 6 also depicts the Raman spectra with the respective $\mathrm{sp}^{3}$ fraction of metallurgical coke breeze, biochar, and deposited carbon. As the $G$ peak shifted slightly towards the right, the extent of graphitization increased. Metallurgical coke breeze was found to be having a higher degree of graphitization, indicating a more ordered carbon structure as compared to the EFB-derived products. As compared to biochar produced by the slow pyrolysis process, the deposited carbon which was originated from tar produced by fast pyrolysis showed a slight shift towards the right in the $G$ peak position. At higher temperatures, the $\mathrm{sp}^{3}$ content was smaller because of increase in graphitization, which also resulted in a more ordered carbon structure and the existence of large carbon crystallites [11].

The results for cluster diameter and $\mathrm{sp}^{3}$ content of the metallurgical coke breeze, EFB biochar, and deposited carbon are plotted in Figure 7. The cluster diameter for coke breeze was the smallest $(2.40 \mathrm{~nm})$ followed by EFB biochar $(3.28 \mathrm{~nm})$ and deposited carbon $(3.90 \mathrm{~nm})$. On the other hand, biochar had the highest $\mathrm{sp}^{3}$ content, followed by deposited carbon and coke breeze. A material with high $\mathrm{sp}^{3}$ content is a highly disordered material having a dispersive structure. Therefore, the results suggested that a biochar produced by the slow pyrolysis process is the most $\mathrm{d}$ isordered material as compared to coke breeze and the deposited carbon, a fast pyrolysis product. This is the reason it was selected as the medium for tar decomposition reaction to take place. In the view of cluster diameter, the deposited carbon recorded the biggest cluster diameter that had been opened up, and this is due to the high processing 


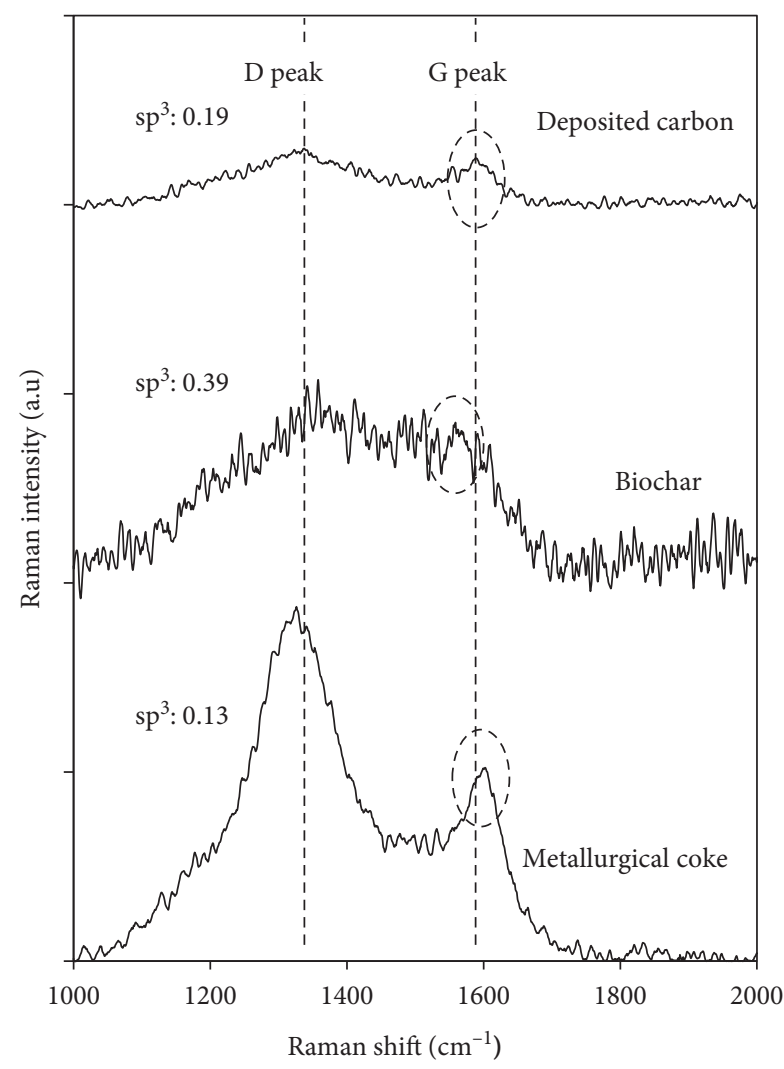

FIGURE 6: Raman spectra of deposited carbon, biochar substrate, and commercial metallurgical coke breeze, indicating the D and G peaks.

temperature and a rapid heating rate than those required to produce biochar.

\subsection{Application of Carbon-Infiltrated Biochar in Sintering} Plant. A sintering plant functions at high temperatures to agglomerate small particles of iron ore together with coke breeze and other fine materials to prepare suitable feedstock for the blast furnace. In a sintering plant operation, coke breeze is the main energy source that undergoes combustion through an oxidation process. This process consumes high energy and produces a large amount of $\mathrm{CO}_{2}$ because of the coke breeze and coke oven gas (COG) combustion. It is crucial to efficiently control the amount of fuel consumption in a sintering plant because it plays a key role in production costs [12].

On the other hand, the effects of biochar utilization as a substitute to coke breeze in a sintering plant on the sinter productivity and quality were reported that an increase of biochar amount in the sintering plant is able to increase the fuel combustion rate. In addition to that, the extent of reduction was also increased in biochar sinter due to its porous structure. However, an approximate 20-25\% replacement of coke breeze with an agricultural residue-derived biochar was found suitable to obtain optimum sinter productivity and sinter quality [13].

Table 1 presents the comparison of EFB-derived biochar and carbon-infiltrated biochar with the commercial coke breeze used in a sintering process. The values for EFB

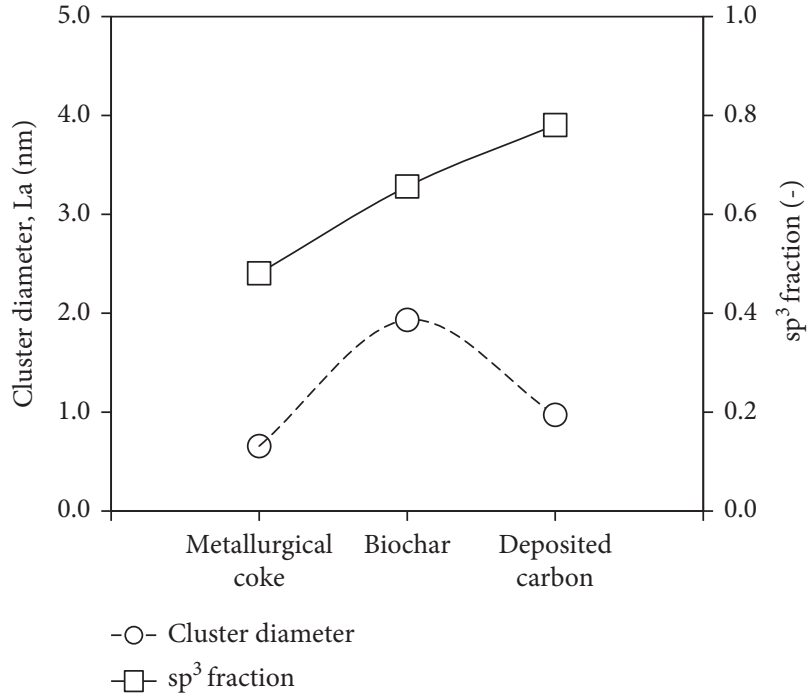

FIgURE 7: Estimation of cluster diameter and $\mathrm{sp}^{3}$ fraction of metallurgical coke breeze, biochar substrate, and the deposited carbon after the tar decomposition process.

biochar and carbon-infiltrated biochar were obtained from experimental data [3], whereas the values for coke breeze were obtained from commercial coke and/or coke breeze data. Having a similar range of particle sizes, carbon content of biochar increased from 63.7 to 69.8 mass $\%$ after the developed integrated pyrolysis-tar decomposition process, which was approaching the minimum carbon content of a commercial coke breeze, 75 mass $\%$. Interestingly, the carbon content of the final carbon-infiltrated biochar product was believed able to be increased further by increasing the amount of tar source [14]. Nevertheless, in this work, the limitation was with the equipment, where the amount of tar source had to be restricted. The calorific value (dry basis, d.b.) of the carbon-infiltrated biochar was also found to be approaching that of a commercial coke breeze. From the values shown Table 1, it can be seen that this developed process to produce carbon-infiltrated biochar managed to help increase and upgrade the value of an EFB-derived biochar to be used as a solid biofuel, with more efficient exergetic performance as compared to conventional biochar production from EFB.

Therefore, utilization of carbon-infiltrated EFB biochar in a sintering plant is deemed to be a promising alternative to coke breeze in the ironmaking industry. Moreover, the gases produced after the tar decomposition process could be used as an energy source as well to become a partial substitute to COG. Figures 8(a) and 8(b) illustrate the schematic diagram of conventional and proposed systems where the proposed system consequently could help to reduce the consumption of coke breeze in a conventional sintering machine. Instead of coke breeze being the only fuel in the sintering plant, carboninfiltrated biochar is proposed to be used as a partial substitute in order to reduce the consumption of the fossil fuel. Carboninfiltrated biochar will be able to be produced by using EFB via the integrated pyrolysis-tar decomposition process in the CVI reactor. The utilization of this EFB-derived carbon-infiltrated 
TABLE 1: Comparison of EFB-derived biochar and carbon-infiltrated biochar with the commercial coke breeze.

\begin{tabular}{lccc}
\hline Material & EFB biochar** & C-infiltrated biochar** & Coke breeze \\
\hline Particle size $(\mathrm{mm})$ & $1.0-3.0$ & $1.0-3.0$ & $0.0-3.0$ \\
Carbon content (\%mass) & $62.9-64.4$ & $68.7-70.5$ & $75.0-85.0$ \\
Calorific value (d.b.*) $(\mathrm{MJ} / \mathrm{kg})$ & $22.9-24.3$ & $25.3-27.2$ & $27.9-30.2$ \\
\hline
\end{tabular}

${ }^{*}$ d.b. $=$ dry basis; ${ }^{* *}$ data collected from the previous study [3].

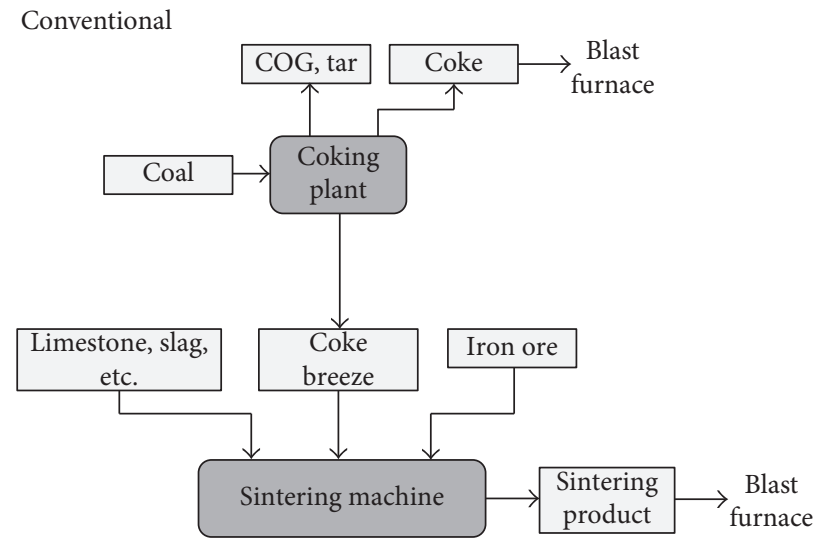

(a)

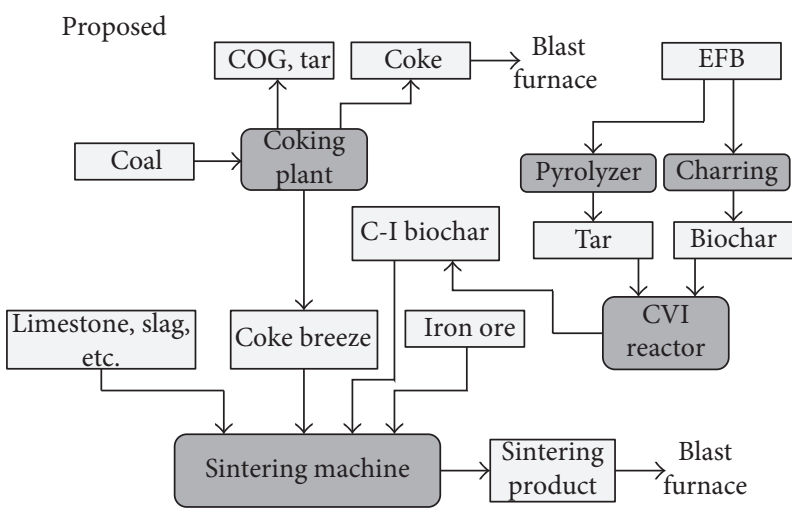

(b)

FIGURE 8: (a) Schematic diagram of conventional system in the sintering machine. (b) Schematic diagram of proposed system for utilization of carbon-infiltrated biochar as a partial substitute to coke breeze in the sintering machine.

biochar could also reduce the emission of $\mathrm{CO}_{2}$ into the environment.

\section{Conclusion}

The mechanism of diffusion was investigated. In this study, for low temperature of biochar production, $400^{\circ} \mathrm{C}$ was selected in order to produce biochar having a small average pore size suitable for Knudsen diffusion to take place. For the tar carbonization process, a low reaction temperature of $400^{\circ} \mathrm{C}$ was selected so that the molecules of tar vapor were less active, to ensure pure Knudsen diffusion to occur, maximizing the amount of carbon able to be deposited within the porous network of biochar. From the pore size distribution plots, the most pores being filled up were the pores in a size range of $2.0-2.5 \mathrm{~nm}$.

The $\mathrm{sp}^{3}$ fractions of the EFB-derived products were calculated in comparison with those of commercial metallurgical coke breeze. The biochar substrate and deposited carbon were categorized as amorphous carbon having 38.67\% and $19.45 \%$ of $\mathrm{sp}^{3}$ content, respectively. As the $\mathrm{sp}^{3}$ contents are higher, the materials become highly reactive due to their dispersive structure. This reactivity characteristic is also important for the product to be used as an energy source in a sintering machine besides its carbon content and calorific value. Metallurgical coke breeze recorded $13 \%$ of $\mathrm{sp}^{3}$ content, which indicated that the produced carbon-infiltrated biochar is more reactive than the commercial coke breeze.

\section{Conflicts of Interest}

The authors declare that they have no conflicts of interest.

\section{Acknowledgments}

This research is partially supported by International Islamic University Malaysia through IIUM Research Initiative Grant Scheme (RIGS 16-353-0517).

\section{References}

[1] Agensi Inovasi Malaysia, National Biomass Strategy 2020: New Wealth Creation for Malaysia's Palm Oil Industry, Agensi Inovasi Malaysia, Cyberjaya, Malaysia, 2011, http://biomass-sp.net/ wp-content/uploads/2012/11/5-Bas-Melssen.pdf.

[2] M. Gavrilescu, "Biomass power for energy and sustainable development," Environmental Engineering and Management Journal, vol. 7, no. 5, pp. 617-640, 2008.

[3] A. N. Rozhan, R. B. Cahyono, N. Yasuda, T. Nomura, S. Hosokai, and T. Akiyama, "Carbon deposition of biotar from pine sawdust by chemical vapor infiltration on steelmaking slag as a supplementary fuel in steelworks," Energy \& Fuels, vol. 26, no. 6, pp. 3196-3200, 2012.

[4] S. H. Kong, S. K. Loh, R. T. Bachmann, S. A. Rahim, and J. Salimon, "Biochar from oil palm biomass: a review of its potential and challenges," Renewable and Sustainable Energy Reviews, vol. 39, pp. 729-739, 2014.

[5] C. Li and K. Suzuki, "Tar property, analysis, reforming mechanism and model for biomass gasification-An overview," Renewable and Sustainable Energy Reviews, vol. 13, no. 3, pp. 594-604, 2009.

[6] J. Welty, C. E. Wicks, G. L. Rorrer, and R. E. Wilson, Fundamentals of Momentum, Heat and Mass Transfer, John Wiley \& Sons Inc., Hoboken, NJ, USA, 2007.

[7] Y. Kameya and K. Hanamura, "Kinetic and raman spectroscopic study on catalytic characteristics of carbon blacks in 
methane decomposition," Chemical Engineering Journal, vol. 173, pp. 627-635, 2011.

[8] M. A. Capano, N. T. McDevitt, R. K. Singh, and F. Qian, "Characterization of amorphous carbon thin films," Journal of Vacuum Science and Technology A: Vacuum, Surfaces, and Films, vol. 14, pp. 431-435, 1996.

[9] M. Kawakami, T. Karato, T. Takenaka, and S. Yokoyama, "Structure analysis of coke, wood charcoal and bamboo charcoal by raman spectroscopy and their reaction rate with $\mathrm{CO}_{2}$," ISIJ International, vol. 45, pp. 1027-1034, 2005.

[10] S. Zeb, M. Sadiq, A. Qayyum, G. Murtaza, and M. Zakaullah, "Deposition of diamond-like carbon film using dense plasma focus," Materials Chemistry and Physics, vol. 103, pp. 235-240, 2007.

[11] X. Zhu and C. Sheng, "Influences of carbon structure on the reactivities of lignite char reacting with $\mathrm{CO}_{2}$ and $\mathrm{NO}$," Fuel Processing Technology, vol. 91, pp. 837-842, 2010.

[12] T. Kronberger, M. Schaler, and C. Schönegger, "Latest generation sinter process optimization systems," in Sintering-Methods and Products, V. Shatokha, Ed., InTech, Shanghai, China, 2012.

[13] E. A. Mousa, A. Babich, and D. Senk, "Iron ore sintering process with biomass utilization," in Proceedings of the METEC and 2nd European Steel Technology and Application Days Conference (METEC and 2nd ESTAD), pp. 1-13, Düsseldorf, Germany, 2015.

[14] A. N. Rozhan, M. H. Ani, H. M. Salleh, T. Akiyama, and H. Purwanto, "Development of carbon-infiltrated bio-char from oil palm empty fruit bunch," ISIJ International, vol. 55, no. 2, pp. 436-440, 2015. 


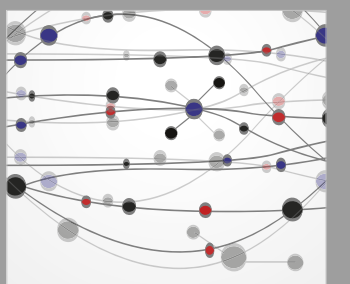

The Scientific World Journal
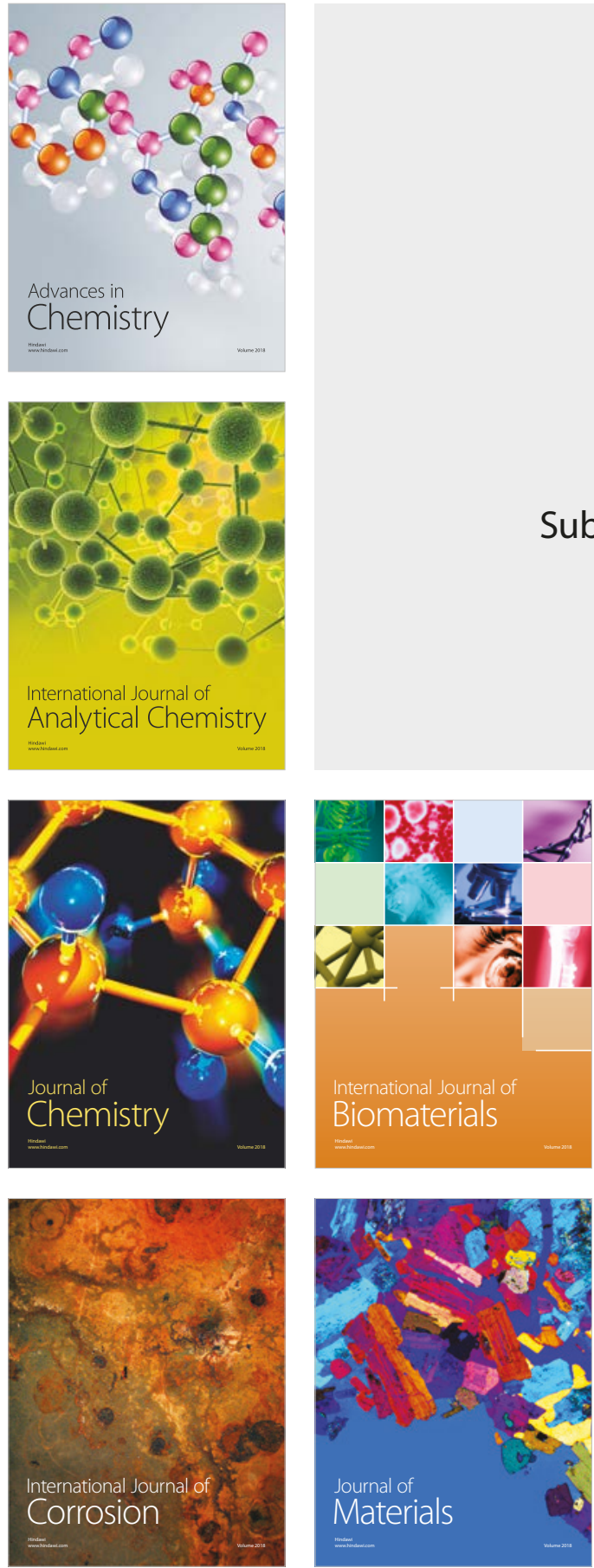

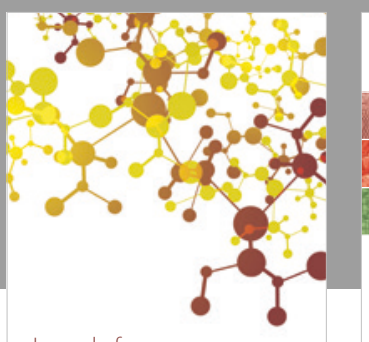

Journal of

Applied Chemistry
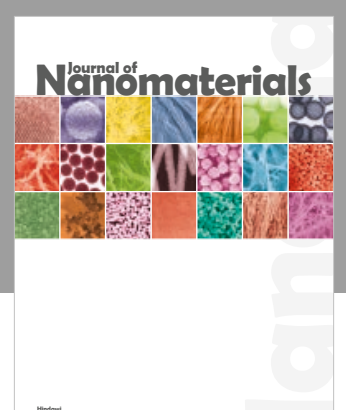

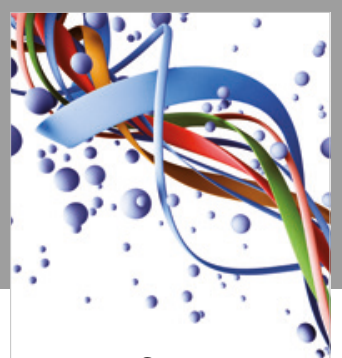

Scientifica

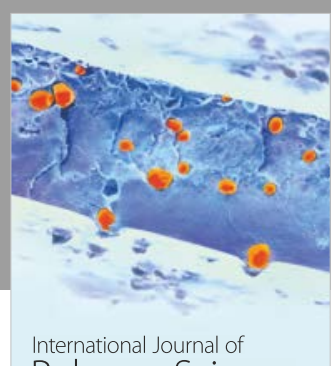

Polymer Science

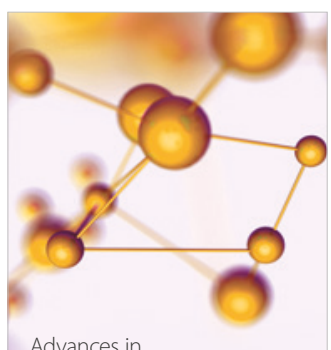

Physical Chemistry
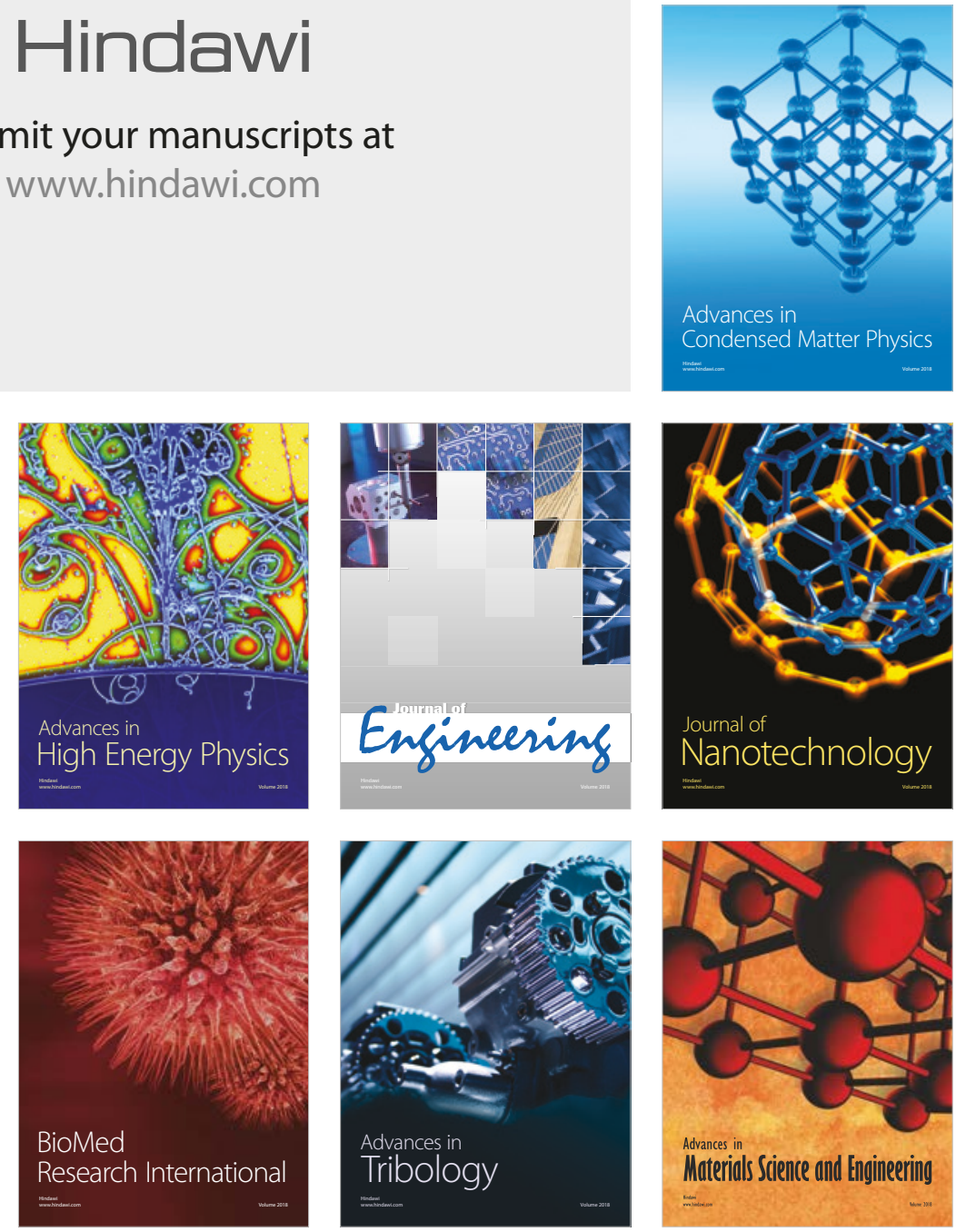